\title{
Selexipag: an oral, selective prostacyclin receptor agonist for the treatment of pulmonary arterial hypertension
}

\author{
Gérald Simonneau*, Adam Torbicki”, Marius M. Hoeper", Marion Delcroix', \\ Kristóf Karlócai ${ }^{\S}$, Nazzareno Galiè ${ }^{\ddagger}$, Bruno Degano*, Diana Bonderman**, \\ Marcin Kurzyna ${ }^{\#}$, Michela Efficace ${ }^{\# \#}$, Ruben Giorgino ${ }^{\# \#}$ and Irene M. Lang**
}

ABSTRACT: In this phase 2 proof-of-concept study we examined the safety and efficacy of selexipag, an orally available, selective prostacyclin receptor (IP receptor) agonist, as a treatment for pulmonary arterial hypertension (PAH).

43 adult patients with symptomatic PAH (receiving stable endothelin receptor antagonist and/or a phosphodiesterase type-5 inhibitor therapy) were randomised three to one to receive either selexipag or placebo. Dosage was up-titrated in $200-\mu \mathrm{g}$ increments from $200 \mu \mathrm{g}$ twice daily on day 1 to the maximum tolerated dose by day 35 (maximum allowed dose of $800 \mu \mathrm{g}$ twice daily). Change in pulmonary vascular resistance at week 17 expressed as a percentage of the baseline value was the primary efficacy end-point, and was analysed in the per protocol set first and then in the all-treated set to assess robustness of results.

A statistically significant $30.3 \%$ reduction in geometric mean pulmonary vascular resistance was observed after 17 weeks' treatment with selexipag compared with placebo (95\% confidence limits -44.7- -12.2; $p=0.0045$, Wilcoxon rank sum test). This was supported by a similar result from the all-treated set. Selexipag was well tolerated with a safety profile in line with the expected pharmacological effect.

Our results encourage the further investigation of selexipag for the treatment of PAH.

KEYWORDS: Haemodynamics, prostacyclin, pulmonary arterial hypertension, randomised controlled trial

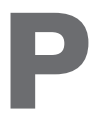
ulmonary arterial hypertension $(\mathrm{PAH})$ is a life-threatening disease of the pulmonary vasculature defined by an elevated mean pulmonary arterial pressure at rest of $\geqslant 25 \mathrm{mmHg}$ and normal pulmonary capillary wedge pressure $(\leqslant 15 \mathrm{mmHg})[1,2]$ in the presence of a normal or reduced cardiac output [1]. Prostacyclin is a member of the prostaglandin family and dysregulation of prostacyclin pathways has been implicated in the pathogenesis of $\mathrm{PAH}$ and provides the rationale for the use of prostacyclin analogues in its treatment [3-6]. These potent vasodilators and inhibitors of platelet aggregation [7, 8] also counteract the vasoconstrictor and prothrombotic activity of endothelin [9]. They bind to the prostacyclin receptor (IP receptor), a G-protein coupled receptor on the surface of platelets and vascular smooth muscle cells [10]. Activation of the receptor leads to production of cyclic adenosine monophosphate, which induces relaxation of vascular smooth muscle.

Epoprostenol, a synthetic prostacyclin analogue administered as a continuous intravenous infusion, was the first targeted PAH therapy to be approved, and improved prognosis for patients with PAH [11-13]. However, complex administration and potentially serious side-effects following acute and chronic administration severely limit its use [3]. Alternatives to epoprostenol include subcutaneously administered treprostinil, which is also available for intravenous and inhaled use in the USA, and inhaled iloprost. While these prostanoids address some of the limitations associated with epoprostenol, they too have drawbacks with respect to frequent dosing (iloprost), injection site pain (subcutaneous treprostinil), and typical prostanoid-associated side-effects such as headache,

\section{AFFILIATIONS}

*AP-HP Hôpital Antoine Béclère, Dept of Pneumology, Clamart, France.

\# Dept of Pulmonary Circulation and Thromboembolic Diseases,

Postgraduate Medical School, ECZOtwock, Warsaw, Poland.

"Hannover Medical School, Hannover, Germany. +University Hospitals (UZ) Leuven, Leuven, Belgium.

${ }^{\S}$ Semmelweis University, Budapest, Hungary.

fUniversity of Bologna, Institute of Cardiology, Bologna, Italy.

${ }^{* \star}$ Medical University of Vienna, Dept of Internal Medicine II, Division of Cardiology, Vienna, Austria.

\#\#Actelion Pharmaceuticals Ltd,

Allschwil, Switzerland.

CORRESPONDENCE

G. Simonneau

National Reference Center for

Pulmonary Hypertension

South Paris University

Hôpital Antoine Béclère

157 rue de la Porte de Trivaux

92141 Clamart Cedex

France

E-mail: gerald.simonneau@

abc.aphp.fr

Received:

Aug 112011

Accepted after revision:

Jan 112012

First published online:

Feb 232012 
flushing, diarrhoea and jaw pain $[4,5,14]$. An oral prostacyclin analogue would be a major advantage in the treatment of $\mathrm{PAH}$. However, all studies thus far with oral prostacyclin analogues, such as beraprost and oral treprostinil, have failed to show a persistent treatment effect as determined by the primary efficacy end-point [14].

Selexipag is an orally available, selective IP receptor agonist. It is rapidly hydrolysed in the hepatic microsomes to an active metabolite [15]. Selexipag and its active metabolite have a higher binding affinity for the human IP receptor than for any other prostanoid receptor [16]. The active metabolite of selexipag has a $>130$-fold higher affinity for the IP receptor than for the prostaglandin receptors [16]. Although selexipag and its metabolite have modes of action similar to that of endogenous prostacyclin (IP receptor agonism), they are chemically distinct from prostacyclin with a different pharmacology. Therefore, selexipag may be an attractive oral alternative to the currently available prostacyclin analogues for the treatment of PAH. The present proof-of-concept study was designed to assess the efficacy, safety and tolerability of selexipag in adult patients with symptomatic PAH.

\section{METHODS}

\section{Patients}

This was a multicentre, multinational, proof-of-concept, phase 2, randomised, double-blind, placebo-controlled, parallel-group trial of 17 weeks' duration.

Eligible patients included male or female adults ( $\geqslant 18 \mathrm{yrs}$ ) with symptomatic PAH of idiopathic or hereditary origin, associated with connective tissue diseases (PAH-CTD), corrected congenital heart disease (congenital systemic-to-pulmonary shunts surgically repaired $\geqslant 5$ yrs previously), or anorexigen use. Background targeted treatment with endothelin receptor antagonists (ERAs) and/or phosphodiesterase type 5 (PDE-5) inhibitors was mandatory and patients had to have been on stable doses for $>12$ weeks before screening. Patients were required to have a baseline pulmonary vascular resistance (PVR) of $>400 \mathrm{dyn} \cdot \mathrm{s} \cdot \mathrm{cm}^{-5}$, and two 6-min walk tests of 150-500 m inclusive and within $\pm 15 \%$ of each other. Patients were excluded if they had had clinically unstable right heart failure within the last 3 months (World Health Organization functional class (WHO FC) IV), had received or were scheduled to receive long-term epoprostenol within 3 months of screening, had a ventilation-perfusion lung scan or pulmonary angiography indicative of thromboembolic disease, had evidence of left-sided heart disease, or had received any investigational drug within 30 days of screening.

The study was approved by the ethics committees or the study centres and was conducted according to the principles of the Declaration of Helsinki and good clinical practice. All patients gave written informed consent prior to study participation.

\section{Procedures}

The randomisation schedule 3:1 (selexipag:placebo) was computer generated by Penn Pharmaceutical Services Ltd (Tredegar, UK). Eligible patients received selexipag $200 \mu \mathrm{g}$ twice daily (synthesised by Nippon Shinkyaku Co., Ltd, Kyoto, Japan) or matching placebo on day 1 . Dosage was then uptitrated to $400 \mu \mathrm{g}$ twice daily on day 3, to $600 \mu \mathrm{g}$ twice daily on day 7 , and to $800 \mu \mathrm{g}$ twice daily on day 21 . A slower up-titration schedule was allowed up to day 35 to allow for a maximum tolerated dose (MTD). Although doses could be temporarily reduced after day 35 to alleviate adverse events, final dosage was required to be stable for $\geqslant 4$ weeks prior to evaluation at week 17.

As the study was blinded, investigators assessed the relationship between adverse events and study treatment before the treatment code was broken. Medical emergency was the only reason to break the codes. For each patient, treatment remained blinded until the final data for week 17 were entered and locked. After week-17 data were fixed and locked, patients eligible to enter the open-label extension were unblinded. For patients who discontinued prematurely or otherwise did not enter the openlabel extension, study treatment remained blinded until all week-17 data were cleaned and reconciled.

Patients underwent right heart catheterisation (RHC) at baseline and at week 17 (days 112-126 inclusive). Week 17 RHC haemodynamic assessments were conducted $4 \mathrm{~h}$ post-dose. Patients who withdrew prematurely or otherwise did not enter the openlabel extension were followed up within 30 days of their last study visit, during which end-of-study assessments were performed along with echocardiography, if possible.

Change in PVR at week 17 expressed as a percentage of the baseline value was chosen as the primary efficacy end-point and summarised using geometric mean and its 95\% two-sided confidence limits (CL). Additional haemodynamic data obtained from RHC were supported by data from secondary efficacy end-points that included established measures of clinical status in PAH patients, such as 6-min walk distance [11], and aggravation of PAH (defined as death, transplantation, hospitalisation due to worsening $\mathrm{PAH}$, or aggravation of PAH symptoms, i.e. $\mathrm{a} \geqslant 10 \%$ deterioration in 6-min walk distance or the need for additional PAH-specific therapies), as well as exploratory end-points, such as Borg dyspnoea score, WHO FC, and plasma N-terminal pro-brain natriuretic peptide (NT-proBNP) concentration [17, 18].

The overall safety and tolerability of selexipag was evaluated in relation to the frequency of treatment-emergent adverse events and premature discontinuation of study treatment, as well as change from baseline to last measurement during the treatment period in vital signs, ECG and laboratory parameters.

\section{Statistical analysis}

A sample size estimation of 44 patients was based on the assumption of a $300-\mathrm{dyn} \cdot \mathrm{s} \cdot \mathrm{cm}^{-5}$ difference in mean change in PVR from baseline to week 17 between treatment groups, a 300dyn $\cdot \mathrm{s} \cdot \mathrm{cm}^{-5}$ common standard deviation, and a 3:1 (selexipag:placebo) randomisation ratio. Such a sample size would provide $80 \%$ power to detect a difference between selexipag and placebo based on a two-sided unpaired t-test at the $5 \%$ significance level.

The primary end-point analysis was based on the per protocol (PP) set, which consisted of all treated patients who did not violate the protocol in a way that might influence the evaluation of the effect of the study drug on the primary end-point. A sensitivity analysis was performed on the all-treated test, which consisted of all patients who had received at least one dose of study drug. Secondary and exploratory efficacy analyses were based on the all-treated set. 


\begin{tabular}{|c|c|c|c|}
\hline \multirow[t]{2}{*}{ TABLE 1} & \multicolumn{3}{|c|}{$\begin{array}{l}\text { Demographics and aetiology of pulmonary } \\
\text { arterial hypertension (PAH) (all-treated set) }\end{array}$} \\
\hline & & Placebo & Selexipag \\
\hline \multicolumn{2}{|c|}{ Subjects n } & 10 & 33 \\
\hline \multicolumn{4}{|c|}{ Demographics } \\
\hline \multicolumn{2}{|c|}{ Male/female } & 2/8 (20.0/80.0) & $6 / 27(18.2 / 81.8)$ \\
\hline \multicolumn{2}{|c|}{ Age yrs } & $53.8 \pm 16.3$ & $54.8 \pm 16.8$ \\
\hline \multicolumn{2}{|l|}{ Weight kg } & $70.6 \pm 13.9$ & $68.7 \pm 12.4$ \\
\hline \multicolumn{2}{|c|}{ Caucasian/other } & $9 / 1(90.0 / 10.0)$ & $29 / 4(88.0 / 12.0)$ \\
\hline \multicolumn{4}{|c|}{ Aetiology of PAH } \\
\hline \multicolumn{2}{|c|}{ Idiopathic PAH } & $7(70.0)$ & $24(72.7)$ \\
\hline \multicolumn{2}{|c|}{ Hereditary PAH } & $1(10.0)$ & $1(3.0)$ \\
\hline \multicolumn{2}{|c|}{ Anorexigen-induced PAH } & & $2(6.1)$ \\
\hline \multicolumn{2}{|c|}{ PAH-CTD } & $2(20.0)$ & $4(12.1)$ \\
\hline \multicolumn{2}{|c|}{$\begin{array}{l}\text { PAH associated with congenial } \\
\text { heart disease }\end{array}$} & & $2(6.1)$ \\
\hline
\end{tabular}

Data are presented as $\mathrm{n}(\%)$ or mean $\pm \mathrm{SD}$, unless otherwise stated. CTD: connective tissue disease.

For each analysis set, missing values at week 17 were imputed with the closest value in time during the treatment period, unless a patient died or experienced disease worsening; then missing values were imputed with the worst value at week 17 over all patients in the analysis set. The Wilcoxon rank sum test with asymptotic approximation to t-distribution (primary) and the t-test (secondary) were used for treatment comparison. Safety and tolerability evaluation was carried out descriptively on the safety set, which consisted of all patients who had received at least one dose of study drug and had at least one post-baseline safety assessment. Post hoc analyses included prevalence of treatment-emergent adverse events over time and adverse events by PAH background therapy.

\section{RESULTS}

\section{Patient demographics and disposition}

Of 45 patients screened, 43 were enrolled at seven centres in seven European countries and randomised to receive either selexipag $200 \mu$ twice daily $(n=33)$ or placebo $(n=10)$, between April 2008 and June 2009 (fig. S1). 40 patients completed the study. Data from 29 patients in the selexipag group and six patients in the placebo group were analysed in the PP set; four patients in each group violated major entry criteria.

Treatment groups were balanced with respect to demographics and aetiologies (table 1) and patients were on stable background PAH therapy (table 2). In the PP set, 11 (37.9\%) patients in the selexipag group were on a combination of ERA and sildenafil therapy versus one $(16.7 \%)$ patient in the placebo group.

Patients on selexipag received treatment for a mean \pm SD of $143.3 \pm 28.6$ days (median 149.0 days; range 17-176 days), compared with $135.1 \pm 27.4$ days (median 146.0 days; range 61152 days) for patients on placebo. Among selexipag-treated patients, $14(42.4 \%)$ were on a final dosage of $800 \mu \mathrm{g}$ twice daily, seven $(21.2 \%)$ were on $600 \mu \mathrm{g}$ twice daily, six $(18.2 \%)$ were on $400 \mu \mathrm{g}$ twice daily and four (12.1\%) were on $200 \mu \mathrm{g}$ twice daily. The MTD could not be determined for two patients due to

\begin{tabular}{|c|c|c|c|}
\hline \multirow[t]{2}{*}{ TABLE 2} & \multicolumn{3}{|c|}{$\begin{array}{l}\text { Disease characteristics and pulmonary arterial } \\
\text { hypertension (PAH) background therapy } \\
\text { (all-treated set) }\end{array}$} \\
\hline & & Placebo & Selexipag \\
\hline \multicolumn{2}{|c|}{ Subjects $\mathrm{n}$} & 10 & 33 \\
\hline \multicolumn{2}{|c|}{ Time from diagnosis yrs } & $4.0 \pm 3.1$ & $5.5 \pm 6.1$ \\
\hline \multicolumn{2}{|c|}{ PVR dyn $\cdot \mathbf{s} \cdot \mathrm{cm}^{-5}$} & $867.2 \pm 379.3$ & $928.6 \pm 436.6$ \\
\hline \multicolumn{2}{|c|}{$\begin{array}{l}\text { 6-min walk distance } \mathrm{m} \\
\text { WHO FC }\end{array}$} & $350.3 \pm 123.5$ & $396.2 \pm 71.4$ \\
\hline \multicolumn{4}{|l|}{$\begin{array}{l}\text { WHO FC } \\
\text { । }\end{array}$} \\
\hline \multicolumn{2}{|l|}{$\|$} & $2(20.0)$ & $15(45.5)$ \\
\hline \multicolumn{2}{|l|}{ III } & $8(80.0)$ & $18(54.5)$ \\
\hline \multicolumn{4}{|l|}{ IV } \\
\hline \multicolumn{2}{|c|}{ Borg dyspnoea score } & $4.1 \pm 2.6$ & $3.3 \pm 2.1^{+}$ \\
\hline \multicolumn{2}{|c|}{ NT-proBNP pg $\cdot \mathrm{mL}^{-1 \#}$} & $2400.9 \pm 1269.8^{\bullet}$ & $1601.4 \pm 2443.0^{5}$ \\
\hline \multicolumn{4}{|c|}{ Background PAH therapy } \\
\hline \multicolumn{2}{|c|}{ ERA monotherapy } & $4(40.0)$ & $12(36.4)$ \\
\hline \multicolumn{2}{|c|}{ Sildenafil monotherapy } & $3(30.0)$ & $9(27.2)$ \\
\hline \multicolumn{2}{|c|}{ ERA plus sildenafil } & $3(30.0)$ & $12(36.4)$ \\
\hline
\end{tabular}

Data are presented as mean \pm SD or $n(\%)$, unless otherwise stated. PVR: pulmonary vascular resistance; WHO FC: World Health Organization functional class; NT-proBNP: N-terminal pro-brain natriuretic peptide; ERA: endothelin receptor antagonist. ${ }^{*}$ : Upper reference values are $100 \mathrm{pg} \cdot \mathrm{mL}^{-1}$ and $172 \mathrm{pg} \cdot \mathrm{mL}^{-1}$ for males aged $45-59$ and $\geqslant 60 \mathrm{yrs}$, respectively, and $164 \mathrm{pg} \cdot \mathrm{mL}^{-1}$ and 225 $\mathrm{pg} \cdot \mathrm{mL}^{-1}$ for females aged $45-59$ and $\geqslant 60 \mathrm{yrs}$, respectively [18]; ${ }^{\circ}: \mathrm{n}=8 ;^{+}: \mathrm{n}=32$; s: $n=27$.

premature treatment discontinuation. Nine (90.0\%) patients on placebo reached MTD of $800 \mu \mathrm{g}$.

\section{Efficacy}

At week 17, PVR (change in geometric mean expressed as a percentage of the baseline value, $95 \% \mathrm{CL}$ ) in the selexipag and placebo groups was $80.7 \%(72.8-89.6 \% ; n=29)$ and $115.9 \%$ $(106.5-126.1 \% ; n=6)$, respectively (fig. 1a). This represented a statistically significant treatment effect of $-30.3 \%(-44.7--12.2 \%$; Wilcoxon rank sum test $\mathrm{p}=0.0045)$. The all-treated analysis, including all 43 patients randomised in the study, confirmed the PP analysis (fig. 1b). Absolute values at baseline, week 17 and change from baseline to week 17 for PVR are provided in online supplementary table S1. Compared with placebo, selexipag treatment seemed to be associated with a mean increase in cardiac index accompanied by a mean decrease in systemic vascular resistance (SVR), with little change in systolic or diastolic blood pressures (tables 3 and 4). The treatment effect on right atrial pressure appeared obscured by the decrease of the high placebo value at baseline (table 3). At week 17, the mean (95\% CL) change from baseline in 6-min walk distance was +24.7 (-1.6-50.9) $\mathrm{m}$ and $+0.4(-19.7-20.5) \mathrm{m}$ in the selexipag and placebo groups, respectively (fig. 2 ).

One $(3.0 \%)$ selexipag-treated patient and two $(20.0 \%)$ placebotreated patients experienced aggravation of PAH. Five (15.6\%) selexipag-treated patients experienced an improvement in WHO FC, compared with one $(10.0 \%)$ placebo recipient. Two patients in each group experienced a worsening of WHO FC. There was no difference between treatments with respect to 

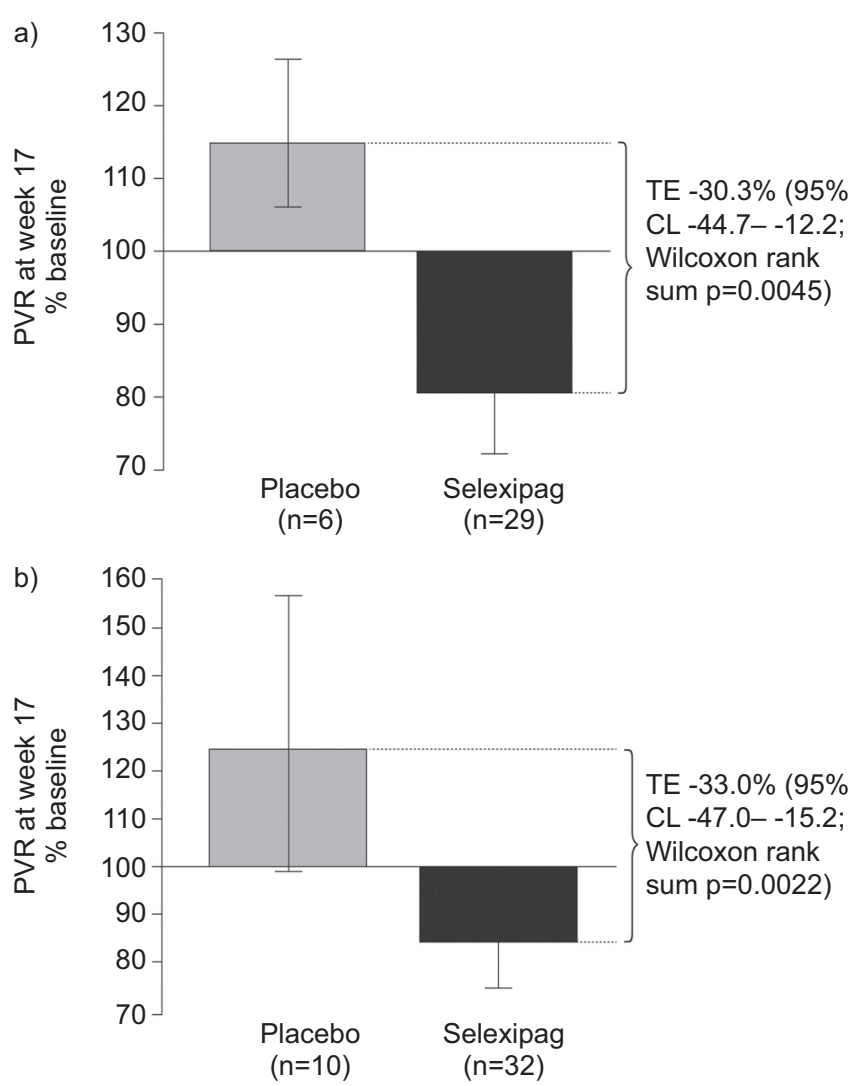

FIGURE 1. Change in pulmonary vascular resistance (PVR) from baseline to week 17. a) Per protocol set and b) all-treated set. Data are presented as means and error bars represent 95\% confidence limits (CL). Baseline PVR values $\left(\right.$ mean \pm SD) for per protocol population for selexipag were $951.9 \pm 434.5 \mathrm{dyn} \cdot \mathrm{s} \cdot \mathrm{cm}^{-5}$ and for placebo were $826.8 \pm 195.8 \mathrm{dyn} \cdot \mathrm{s} \cdot \mathrm{cm}^{-5}$. Baseline PVR values (mean $\pm \mathrm{SD}$ ) for the all-treated population for selexipag were $948.6 \pm 428.0 \mathrm{dyn} \cdot \mathrm{s} \cdot \mathrm{cm}^{-5}$ and for placebo were $867.2 \pm 379.38 \mathrm{dyn} \cdot \mathrm{s} \cdot \mathrm{cm}^{-5}$. TE: treatment effect.

Borg dyspnoea score (mean treatment effect -0.1 units, 95\% CL -1.4-1.1) or plasma NT-proBNP (mean treatment effect $\left.-212.8 \mathrm{pg} \cdot \mathrm{mL}^{-1}, 95 \% \mathrm{CL}-1,012.1-586.5 \mathrm{pg} \cdot \mathrm{mL}^{-1}\right)$.

\section{Safety}

Almost all patients in both treatment groups experienced at least one adverse event, with headache, pain in jaw, pain in an extremity, nausea, and nasopharyngitis being the most frequently reported in the selexipag group (table 5). The majority of adverse events in the selexipag group were classified as mild $(n=5 ; 15.2 \%)$ or moderate $(n=20 ; 60.6 \%)$. Six $(18.2 \%)$ patients in the selexipag group and four $(40.0 \%)$ in the placebo groups experienced at least one serious adverse event (online supplementary table S2). Serious adverse events considered by the investigator to be at least possibly related to selexipag treatment included headache, nausea, vomiting, myalgia, dyspnoea and chest pain. None of the events on placebo were considered to be related to the study drug. There were no deaths. Post hoc analysis showed that there was no difference in adverse events between treatment groups when stratified by background therapy, i.e. ERA or PDE-5 inhibitor monotherapy, or ERA plus PDE-5 inhibitor combination therapy. Prevalence of adverse events associated with prostacyclin analogue treatment, such

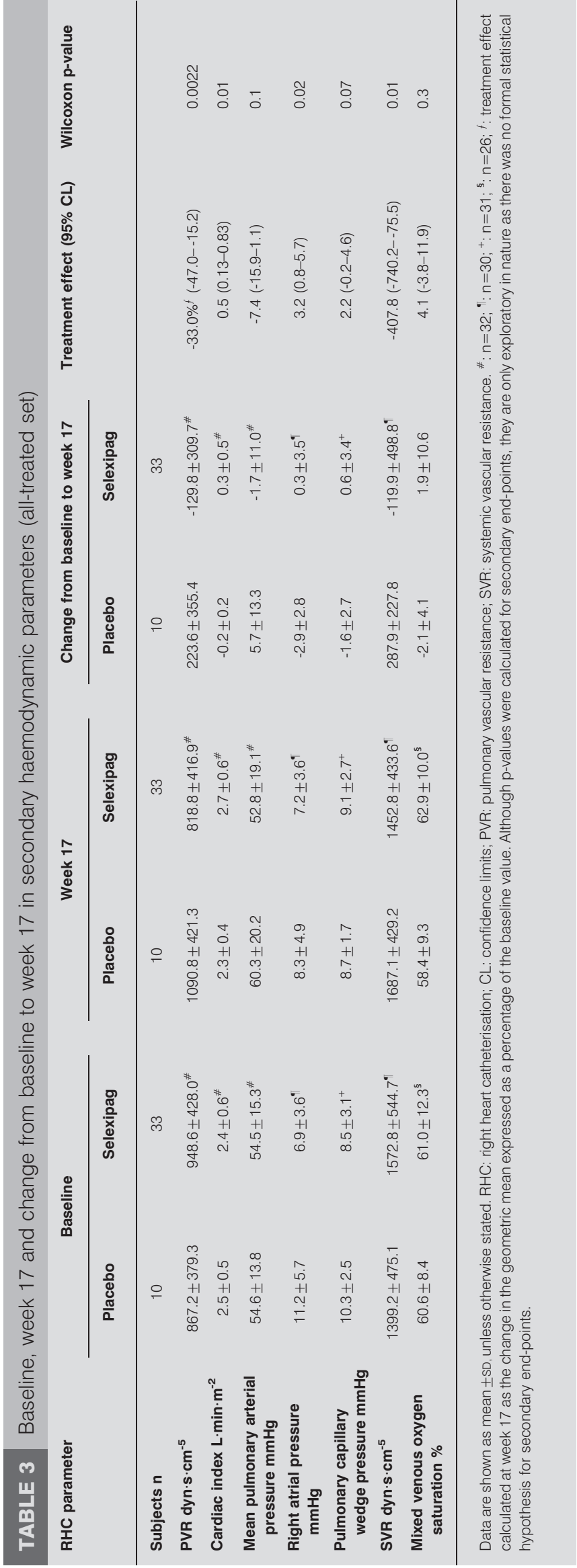




\begin{tabular}{|c|c|c|c|c|c|c|}
\hline \multirow[t]{2}{*}{ Vital signs parameter ${ }^{\#}$} & \multicolumn{2}{|c|}{ Baseline } & \multicolumn{2}{|c|}{ End of study period } & \multicolumn{2}{|c|}{$\begin{array}{l}\text { Change from baseline to } \\
\text { end of study period }\end{array}$} \\
\hline & Placebo & Selexipag & Placebo & Selexipag & Placebo & Selexipag \\
\hline Diastolic blood pressure $\mathrm{mmHg}$ & $66.8 \pm 10.4$ & $65.9 \pm 10.9$ & $70.0 \pm 9.8$ & $71.8 \pm 9.1$ & $3.2 \pm 12.8$ & $5.4 \pm 11.2$ \\
\hline Heart rate beats $\cdot \mathrm{min}^{-1}$ & $74.8 \pm 13.2$ & $75.3 \pm 15.8$ & $77.9 \pm 10.5$ & $75.2 \pm 12.1$ & $3.1 \pm 6.0$ & $-0.1 \pm 7.7$ \\
\hline
\end{tabular}

Data are presented as mean $\pm \mathrm{SD} .{ }^{\#}$ : Treatment effect was not calculated for these safety parameters.

as headache, pain in an extremity, pain in jaw, nausea and diarrhoea, decreased over time in patients treated with selexipag (online supplementary table S3). No clinically relevant changes in vital signs from baseline to week 17 , including blood pressure, and pulse rate, ECG parameters, including QT interval changes, and laboratory tests, were observed.

\section{DISCUSSION}

This proof-of-concept phase 2 study was designed to provide preliminary evidence of the efficacy and tolerability of selexipag in patients with PAH. The study showed a significant $30.3 \%$ reduction in PVR after 17 weeks' treatment with selexipag, compared with placebo. PVR has previously been used as an indicator of treatment benefit [19] and probably relates to longterm outcomes in PAH $[12,13]$. Furthermore, marked reductions in PVR have been reported with epoprostenol, the synthetic form of prostacylin [20]. Improvements in other haemodynamic parameters, such as an increase in cardiac index and a decrease in SVR, may be explained by the vasodilatory effect of IP receptor agonism. However, the decrease in SVR was not accompanied by systemic hypotension. The beneficial effects with selexipag were observed despite patients receiving background therapy with an ERA and/or sildenafil, with approximately one third of

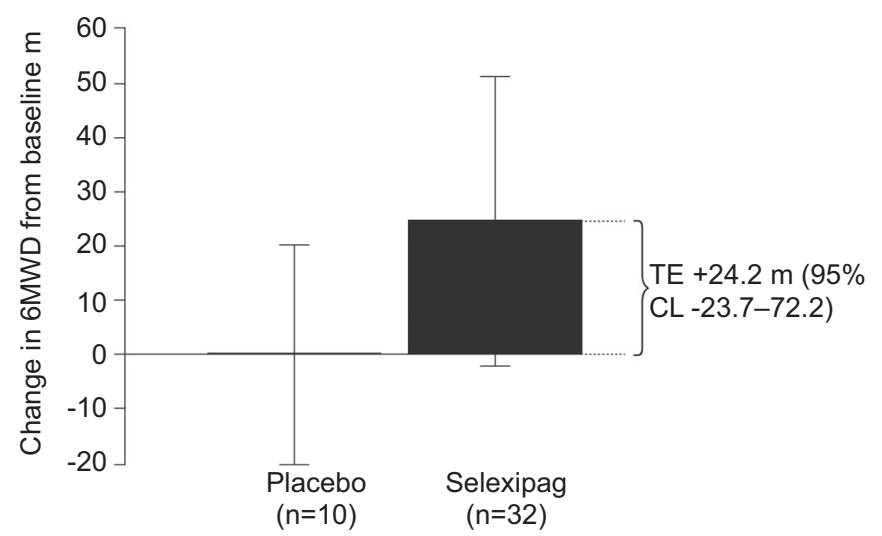

FIGURE 2. Change in 6-min walk distance (6MWD) from baseline to week 17 (all-treated population). Baseline values (mean $\pm \mathrm{SD}$ ) for selexipag were $394.7 \pm 72.0 \mathrm{~m}$ and for placebo were $350.3 \pm 123.5 \mathrm{~m}$. Week 17 values (mean \pm SD) for selexipag were $419.3 \pm 106.3 \mathrm{~m}$ and for placebo were $350.7+139.6 \mathrm{~m}$. TE: treatment effect: $\mathrm{CL}$ : confidence limits. patients on a combination of the two. Patients with PAH often require more than one therapy because of clinical deterioration or failure to achieve specified treatment goals. The efficacy of add-on or combination therapy with drugs of different modalities, such as ERAs and PDE-5 inhibitors, has been evaluated and is recommended in current treatment guidelines [1].

Statistically significant treatment effects were not observed for the secondary parameters of 6-min walk distance or the exploratory parameter of NT-proBNP. Given that the study was not powered to detect differences in these parameters, this is not an entirely unexpected result. The magnitude of the placebocorrected mean treatment effect of $+24.2 \mathrm{~m}$ on the 6 -min walk distance was similar to that obtained at week 24 in the phase 2 proof-of-concept study of imatinib $(+21.7 \mathrm{~m})$ [21]. Statistical significance for this parameter was not met in this trial either. As in our study, patients in the imatinib trial were on background $\mathrm{PAH}$ therapies, which may have contributed to the lack of significant improvement on 6-min walk distance. With regards to NT-proBNP, there was a baseline difference between placeboand selexipag-treated patients. This, together with the large

\section{TABLE 5 Treatment-emergent adverse events during the} study (safety set)

\begin{tabular}{lcc} 
Adverse events & Placebo & Selexipag \\
\hline Subjects & 10 & 33 \\
Patients with $\geqslant \mathbf{1}$ & 10 & 31 \\
$\quad$ adverse event & & \\
Adverse events $>\mathbf{1 0} \%$ & & \\
$\quad$ on selexipag & 2 & 22 \\
Headache & & 12 \\
Jaw pain & & 10 \\
Pain in an extremity & & 9 \\
Nausea & 2 & 8 \\
Nasopharyngitis & 1 & 6 \\
Diarrhoea & & 6 \\
Flushing & & 5 \\
$\quad$ Dizziness & & 4 \\
Cough & & 4 \\
Myalgia & & \\
\hline
\end{tabular}

Data are presented as $n$. 
standard deviations of the mean at baseline and at the end of the study, means it was unlikely that a treatment difference in our study would have been observed.

17 weeks' treatment with selexipag was well tolerated by most patients in this study. Adverse events were consistent with the known side-effect profile of IP receptor agonism and were similar in nature to those reported in the 12-week trial of the oral prostacyclin beraprost [22]. There was a marked reduction in the incidence of adverse events in the maintenance phase of the beraprost study compared with the titration phase. Similarly, post hoc analysis of the selexipag data showed that the prevalence of some adverse events, such as headache, pain in jaw, pain in an extremity and flushing, decreased over time. It is likely that they were related to the rapid up-titration to MTD. The up-titration protocol was relatively aggressive and patients could remain hospitalised for 1 week after the first dose. Consequently, $63.6 \%$ of selexipag-treated patients achieved a final optimal dose of $600 \mu \mathrm{g}$ twice daily or higher. However, a longer up-titration phase could have permitted even more patients to reach the highest dose in this study (800 $\mu \mathrm{g}$ twice daily), or potentially even higher doses.

The 3:1 randomisation ratio, together with the small sample size, may have contributed to the imbalances seen between the treatment groups in respect to some of the disease characteristics such as WHO FC, 6-min walk distance and NT-proBNP, which suggested that patients on placebo were in a worse condition than those in the active group. Additionally, the PP analysis resulted in an active drug to placebo ratio of 5:1, with four patients in each treatment arm excluded due to major protocol violations. This does limit generalisation of the results of this study. Even so, the treatment effect on PVR was consistent for the PP analysis and the all-treated sensitivity analysis, which included all 43 randomised patients. There were also positive trends for some of the secondary outcomes measures, which we consider sufficient in a proof-of-concept study in a rare and fatal disease to support continued investigation of selexipag in larger scale studies. Our study lacked the potential to go beyond a prespecified maximum dose of selexipag $800 \mu \mathrm{g}$ twice daily. However, higher doses of selexipag are being investigated in the current ongoing phase 3 study.

Selexipag is an orally available, selective IP receptor agonist with the potential to address some of the pharmacokinetic and safety limitations associated with prostacyclin analogues. The active metabolite of selexipag has a relatively long elimination half-life of $7.9 \mathrm{~h}$ that permits twice-daily dosing and contrasts with prostacyclin analogues that require continuous or very frequent dosing to achieve a sustained response [16, 23]. Adverse events related to prostacyclin analogues are often due to the abrupt changes of the plasma levels of the drug. As selexipag is rapidly hydrolysed in the liver to the active metabolite, peak-trough fluctuations in serum levels of active compound may be reduced, thereby reducing the likelihood of adverse events [16]. In addition, continuous vasodilation induced by exposure to selexipag is not attenuated by repetitive dosing, suggesting that severe desensitisation of the IP receptor is unlikely [16]. Thus, there may be less need for dose escalation to maintain efficacy.

In conclusion, this proof-of-concept study showed that treatment with selexipag resulted in a statistically significant $30.3 \%$ reduction in PVR after 17 weeks, which was supported by an increase in cardiac index and a decrease in SVR without systemic hypotension. Selexipag was well tolerated, with a safety profile in line with that of the expected pharmacological effect. Overall, the results of this study encourage further investigation of selexipag in PAH.

\section{CLINICAL TRIAL}

This study is registered at clinicaltrials.gov with identifier number NCT00993408.

\section{STATEMENT OF INTEREST}

Statements of interest for G. Simonneau, A. Torbicki, M.M. Hoeper, M. Delcroix, K. Karlócai, N. Galiè, M. Kurzyna, M. Efficace, R. Giorgino and I.M. Lang, and for the study itself can be found at www.erj. ersjournals.com/site/misc/statements.xhtml

\section{ACKNOWLEDGEMENTS}

We gratefully acknowledge all investigators involved in this study. The authors thank L. Thomas (Elements Communications, Westerham, UK) for providing medical writing assistance.

\section{REFERENCES}

1 Galiè N, Hoeper MM, Humbert M, et al. Guidelines for the diagnosis and treatment of pulmonary hypertension. Eur Respir J 2009; 34: 1219-1263.

2 McLaughlin VV, Archer SL, Badesch DB, et al. ACCF/AHA 2009 expert consensus document on pulmonary hypertension: a report of the American College of Cardiology Foundation Task Force on Expert Consensus Documents and the American Heart Association: developed in collaboration with the American College of Chest Physicians, American Thoracic Society, Inc., and the Pulmonary Hypertension Association. Circulation 2009; 119: 2250-2294.

3 Christman BW, McPherson CD, Newman JH, et al. An imbalance between the excretion of thromboxane and prostacyclin metabolites in pulmonary hypertension. N Engl J Med 1992; 327: 70-75.

4 Galiè N, Manes A, Branzi A. Prostanoids for pulmonary arterial hypertension. Am J Respir Med 2003; 2: 123-137.

5 Badesch DB, McLaughlin VV, Delcroix M, et al. Prostanoid therapy for pulmonary arterial hypertension. J Am Coll Cardiol 2004; 43: 56S-61S.

6 Barst RJ, Gibbs JS, Ghofrani HA, et al. Updated evidence-based treatment algorithm in pulmonary arterial hypertension. J Am Coll Cardiol 2009; 54: S78-S84.

7 Moncada S, Gryglewsli R, Bunting S, et al. An enzyme isolated from arteries transforms prostaglandin endoperoxides to an unstable substance that inhibits platelet aggregation. Nature 1976; 263: 663-665.

8 Clapp LH, Finney P, Turcato S, et al. Differential effects of stable prostacyclin analogs on smooth muscle proliferation and cyclic AMP generation in human pulmonary artery. Am J Respir Cell Mol Biol 2002; 26: 194-201.

9 Worst SJ, Woods M, Warner TD, et al. Cyclooxygenase-2 acts as an endogenous brake on endothelin-1 release by human pulmonary artery smooth muscle cells: implications for pulmonary hypertension. Mol Pharmacol 2002; 62: 1147-1153.

10 Stitham J, Arehart EJ, Gleim SR, et al. New insights into human prostacyclin receptor structure and function through natural and synthetic mutations of transmembrane charged residues. $\mathrm{Br} J$ Pharmacol 2007; 152: 513-522.

11 Barst RJ, Rubin LJ, Long WA, et al. A comparison of continuous intravenous epoprostenol (prostacyclin) with conventional therapy for primary pulmonary hypertension. N Engl J Med 1996; 334: 296-302. 
12 McLaughlin VV, Shillington A, Rich S. Survival in primary pulmonary hypertension: the impact of epoprostenol therapy. Circulation 2002; 106: 1477-1482.

13 Sitbon $\mathrm{O}$, Humbert $\mathrm{M}$, Nunes $\mathrm{H}$, et al. Long-term intravenous epoprostenol infusion in primary pulmonary hypertension: prognostic factors and survival. J Am Coll Cardiol 2002; 40: 780-788.

14 White RJ. Update on the development of oral prostacyclin analogs for the treatment of PAH. Adv Pulmonary Hypertens 2009; 8: 32-36.

15 Mubarak KK. A review of prostaglandin analogs in the management of patients with pulmonary arterial hypertension. Respir Med 2010; 104: 9-21.

16 Kuwano K, Hashino A, Asaki T, et al. NS-304, an orally available and long-acting prostacyclin receptor agonist prodrug. J Pharmacol Exp Ther 2007; 322: 1181-1188.

17 Channick RN, Simonneau G, Sitbon O, et al. Effects of the dual endothelin-receptor antagonist bosentan in patients with pulmonary hypertension: a randomised placebo-controlled trial. Lancet 2001; 358: 1119-1123.

18 Galasko GI, Lahiri A, Barnes SC, et al. What is the normal range for $\mathrm{N}$-terminal pro-brain natriuretic peptide? How well does this normal range screen for cardiovascular disease? Eur Heart J 2005; 26: $2269-2276$.
19 Galiè N, Rubin LJ, Hoeper MM, et al. Treatment of patients with mildly symptomatic pulmonary arterial hypertension with bosen$\tan$ (EARLY study): a double-blind, randomised controlled trial. Lancet 2008; 371: 2093-2100.

20 McLaughlin VV, Genthner DE, Panella MM, et al. Reduction in pulmonary vascular resistance with long-term epoprostenol (prostacyclin) therapy in primary pulmonary hypertension. N Engl J Med 1998; 338: 273-277.

21 Ghofrani HA, Morrell NW, Hoeper MM, et al. Imatinib in pulmonary arterial hypertension patients with inadequate response to established therapy. Am J Respir Crit Care Med 2010; 182: 1171-1177.

22 Galiè N, Humbert M, Vachiéry JL, et al. Arterial Pulmonary Hypertension and Beraprost European (ALPHABET) Study Group. Effects of beraprost sodium, an oral prostacyclin analogue, in patients with pulmonary arterial hypertension: a randomized, double-blind, placebo-controlled trial. J Am Coll Cardiol 2002; 39: 1496-1502.

23 Kuwano K, Hashino A, Noda K, et al. A long-acting and highly selective prostacyclin receptor agonist prodrug, NS-304, ameliorates rat pulmonary hypertension with unique relaxant responses of its active form MRE-269 on rat pulmonary artery. J Pharmacol Exp Ther 2008; 326: 691-699. 